\title{
REDUCED-SCALE STUDY OF LIQUID FUEL STORAGE TANK FIRE USING FIRE DYNAMICS SIMULATOR
}

\author{
F. R. Centeno ${ }^{\mathrm{a}, \mathrm{b}}$, \\ and E. E. C. Rodrigues ${ }^{b}$ \\ ${ }^{a}$ Universidade do Vale do Rio dos Sinos \\ PPG em Engenharia Mecânica \\ Bairro Cristo Rei \\ CEP 93022-000, São Leopoldo, RS, Brasil \\ frcenteno@unisinos.br \\ ${ }^{\mathrm{b}}$ Universidade do Vale do Rio dos Sinos \\ Instituto Tecnológico em Desempenho e \\ Construção Civil \\ Bairro Cristo Rei \\ CEP 93022-000, São Leopoldo, RS, Brasil \\ Received: March 04, 2015 \\ Revised: April 06, 2015 \\ Accepted: May 07, 2015
}

ABSTRACT

Most of the accidents that occur in liquid fuel storage tank parks are caused by fire. This paper presents a numerical study using Large Eddy Simulation through Fire Dynamics Simulator (FDS) for the simulation of liquid fuel (ethanol) storage tanks at different scales (real-scale 1:1, and reducedscales, 1:2, 1:4, 1:8). This paper proposes correlations for flame height, and temperature profile and radiative heat flux profile in the region adjacent to the tanks. Correlations have as inputs the diameters of the tanks in real- and reduced-scale, temperature profiles and radiative heat flux profiles for a reduced-scale tank simulation, and then provide as outputs flame height and temperature profiles and radiative heat flux profiles for the tank in realscale. Percentage errors of the correlations found in this study are lower than $2.0 \%$ and $0.6 \%$ for the maximum radiative heat flux and maximum temperature, respectively.

Keywords: fuel storage tank, fire, fire dynamics simulator, reduced-scale

\section{NOMENCLATURE}

d tank diameter (reduced-scale), $\mathrm{m}$

$D$ tank diameter (real-scale), $\mathrm{m}$

$L_{f} \quad$ flame height, $\mathrm{m}$

$q_{\text {rad }}^{\prime \prime} \quad$ average radiative heat flux, $\mathrm{kW} / \mathrm{m}^{2}$

$\dot{Q} \quad$ heat release rate, $\mathrm{kW}$

$t$ time, s

$T$ average temperature, ${ }^{\circ} \mathrm{C}$

$x, y, z$ coordinates, $\mathrm{m}$

\section{Greek symbols}

$\beta$ parameter to compute radiative heat flux profile, dimensionless

\section{Subscripts \\ d reduced-scale tank \\ $D$ real-scale tank \\ $f \quad$ final}

\section{INTRODUCTION}

Taking into account the worldwide growing demand for energy together with economic development, storage of liquid fuel in multiple tanks is a reality that arises challenges related to fire safety. Chang and Lin (2006) presented a literature review of two hundred forty two accidents of storage tanks that occurred in industrial facilities over forty years. Results shown that $74 \%$ of the accidents occurred in petroleum refineries, oil terminals or storage parks, while fire and explosion account for $85 \%$ of the accidents. Fuel storage tanks are usually clustered in tank parks, and then a fire nucleated in one tank could lead to a domino effect in which fire propagates from one tank to another. This effect could be responsible to major damages to the storage park and to the life of workers. Therefore, among the risks associated to liquid fuel storage tanks, fire is one of the most worrying.

Literature presents some experimental and numerical studies related to fuel storage tanks. Wen-he et al. (2013) performed a numerical simulation using Fluent to analyze thermal radiation from a large crude oil tank. The safe distance to install LPG (Liquefied Petroleum Gas) tanks in houses and industries during a possible wildland fire was experimentally studied in Heymes et al. (2013). A numerical and experimental investigation was performed (Zheng et al., 2013) aiming to check the applicability and the validity of a standard test for high-pressure hydrogen storage tanks exposed to localized fire. Godoy and Batista-Abreu (2012) presented a computational modeling of steel storage tanks under heat induced by an adjacent fire in order to study its structural behavior. Qiang et al. (2012) investigated the effects of spray distance and sprinkler pressure on the effectiveness of controlling the fire in a fuel tank of an emergency diesel generator using the software FDS. FDS was also employed in Lin and Wang (2011) with the objective of analyzing safe distances between liquid fuel 
storage tanks in order to avoid that fire spreads from one tank to another leading to damage to the whole tank park. Silva et al. (2013) studied safety conditions (spacing between tanks and actuation of sprinklers) for liquid fuel storage tanks using FDS. Despite the great importance of that topic, literature is not yet complete in this research area, neither in experimental nor in numerical works.

There are some works in the literature related to fire in reduced-scale, both numerical and experimental, covering buildings, houses, tunnels and wildland (Overholt et al., 2014; Adam et al., 2013; Bryner et al., 1995; Ryder et al., 2004). Zhang et al. (2014) performed a small-scale experimental study on the fireproof distance of oil tank fires in several wind intensity conditions. The principles for scaling fire phenomena are examined in Quintiere (1989) from fourteen dimensionless groups derived from the governing differential equations. Also, scaling techniques based on Froude modeling, pressure modeling and analog modeling are described and illustrated. Such techniques satisfy only one or two dimensionless groups and they are restricted to specific scenarios. Experimental studies of fire phenomena in laboratory-scale employing dimensionless groups can provide a general insight of the transport mechanisms and behavior of the realscale system, but generally, they do not provide quantitatively precise results. Increasing in liquid fuel demand in conjunction to the risks related to its storage are the motivation to investigate heat transfer and combustion processes in storage tanks fire. That could be applicable to evaluate safety standards presented in firefighting and fire prevention regulations.

Performing fire experiments in real-scale tanks is unfeasible due to dimensions and operational safety risks, emerging the use of reduced-scale models and its validation. In this manner, the objective of the present work is the development of a numerical methodology via Computational Fluid Dynamics (CFD) employing the software FDS through numerical experiments in reduced-scale to perform a thermal evaluation of liquid fuel storage tanks under accidental fire conditions. Numerical simulations are performed to obtain correlations between results for reduced-scale tanks simulations as compared to results for real-scale tank simulations.

\section{METHODOLOGY}

CFD codes, in particular Large Eddy Simulation (LES), are a powerful and efficient tool to fire modeling. That tool is capable of predicting fire effects, including plume characteristics, pollutant dispersion, and heat transfer to objects adjacent to the fire source.

According to McGrattan et al. (2007), the software Fire Dynamics Simulator (FDS), a LES code developed by NIST (National Institute of
Standards and Technology), is ideal to simulate realistic geometries of explosions and fire in large scales, and it has several advantages in relation to traditional CFD codes. Transient simulations of fires and explosions can be performed using hardware less sophisticated (less cost) than the necessary to traditional CFD codes (PC-type computer versus UNIX workstations). Also, FDS allows solutions for long time-histories with minimal computational resources (processing-CPU times of the order of hundreds of minutes, depending on mesh resolution and on geometry size).

FDS, selected to run the simulations in the present work, is based on the finite volume method and it solves numerically Navier-Stokes equations appropriate to low velocity ("low-Mach number approximation”) and buoyancy-driven flows, with emphasis on smoke transport and heat transfer in fires. Its basic algorithm employs an explicit corrector-predictor scheme, second-order accuracy on time and on space. For the gas-phase, the hydrodynamic model includes equations for momentum conservation, energy and chemical species. Turbulence is treated with Deardorff subgrid model (Deardorff, 1972). Thermal radiation is computed using a finite volume method over the same grid employed to solve flow equations, while radiant properties modeling is performed with a graygas model. The solid angle is discretized on one-hundred discrete angles. Combustion model is based on mixture fraction with a single-step global chemical reaction. It is considered that combustion is controlled by the turbulent mixture with infinitely fast reaction between fuel and oxygen, independently from temperature. Lagrangean particles are employed to simulate smoke movement. Along its development at NIST, FDS was optimized to solve practical fire problems related to fire protection engineering and it is also a tool to investigate fundamentals of fire dynamics and combustion (McGrattan et al., 2007).

\section{PROBLEM STATEMENT}

The problem consists in numerically solving several liquid fuel storage tanks under fire condition. In this work, the real-scale tank has $4 \mathrm{~m}$ diameter and $1 \mathrm{~m}$ height. Besides the simulation for the real-scale tank, the computational domain is down-scaled and additional simulations are performed for reducedscale tanks: 1:2, 1:4, 1:8. Table 1 shows different cases studied in this work, from scale 1:1 (real-scale) to scale 1:8 (smallest domain considered for simulation). For each case, Table 1 presents: scale, tank diameter, tank height, computational domain dimensions (tridimensional domain in cartesian coordinates).

Figure 1 presents the computational domain sketch where it is observed geometric relations for tank diameter (D), tank height, and domain dimensions (width $4 \mathrm{D} \times$ length $4 \mathrm{D} \times$ height $4 \mathrm{D}-$ 
height is not plotted in Fig. 1). Fuel selected for simulations was ethanol. Except the south boundary of the domain (ground), all other boundaries (north, east, west, front, back) were set open, representing a storage tank installed in an open field. Other boundary conditions were kept standard ones of FDS. Figure 1 also shows positions from where average temperature profiles and average radiant heat flux profiles were extracted.

Table 1. Tank dimensions and computational domain dimensions for each case simulated.

\begin{tabular}{|c|c|c|c|}
\hline Scale & $\begin{array}{c}\text { Tank } \\
\text { Diameter }\end{array}$ & $\begin{array}{c}\text { Tank } \\
\text { Height }\end{array}$ & $\begin{array}{c}\text { Computational } \\
\text { Domain Dimensions }\end{array}$ \\
\hline $1: 1$ & $4.0 \mathrm{~m}$ & $1.000 \mathrm{~m}$ & $16 \mathrm{~m} \times 16 \mathrm{~m} \times 16 \mathrm{~m}$ \\
\hline $1: 2$ & $2.0 \mathrm{~m}$ & $0.500 \mathrm{~m}$ & $8 \mathrm{~m} \times 8 \mathrm{~m} \times 8 \mathrm{~m}$ \\
\hline $1: 4$ & $1.0 \mathrm{~m}$ & $0.250 \mathrm{~m}$ & $4 \mathrm{~m} \times 4 \mathrm{~m} \times 4 \mathrm{~m}$ \\
\hline $1: 8$ & $0.5 \mathrm{~m}$ & $0.125 \mathrm{~m}$ & $2 \mathrm{~m} \times 2 \mathrm{~m} \times 2 \mathrm{~m}$ \\
\hline
\end{tabular}

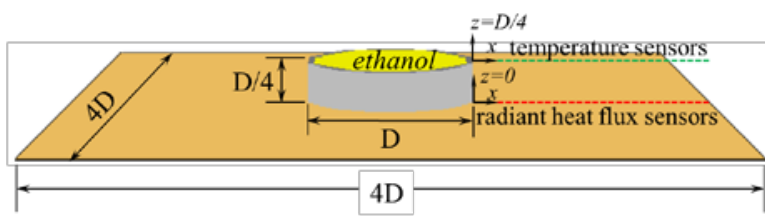

Figure 1. Ethanol storage tank computational domain.

Relatively to the time discretization, the initial time step is automatically set dividing the smallest mesh cell size by the flow characteristic velocity. During calculations, the time step is adjusted in such a manner that the CFL (Courant, Friedrichs, Lewy) condition is satisfied (McGrattan et al., 2007). Then, time steps for simulations in real-scale and reducedscales were, aproximately, $\Delta t=5.0 \times 10^{-3} \mathrm{~s}, \Delta t=4.0$ $\times 10^{-3} \mathrm{~s}, \Delta t=3.0 \times 10^{-3} \mathrm{~s}$, e $\Delta t=1.5 \times 10^{-3} \mathrm{~s}$, for scales $1: 1,1: 2,1: 4$ and $1: 8$, respectively. Simulations were taken to a final time of $t_{\mathrm{f}}=60.0 \mathrm{~s}$, and the interval of $50.0 \leq t \leq 60.0 \mathrm{~s}$ was employed to determine average and statistical parameters for the temperature field and for the radiant heat flux field. Computational CPU times for each simulation were about $9.90 \times 10^{4} \mathrm{~s}, 1.26 \times 10^{5} \mathrm{~s}, 1.76 \times 10^{5} \mathrm{~s}$ and 2.40 $\times 10^{5}$ s for simulations in scales $1: 1,1: 2,1: 4$ and $1: 8$, respectively. For all cases studied, spatial domain was discretized in $100 \times 100 \times 100$ volumes in directions $x, y$ and $z$. Such spatial resolution can be considered adequately refined to solve flow field and fire dynamics since the relationship between the characteristic diameter of fire (which is proportional to the heat release rate) and the control volumes size is satisfied (Stroup and Lindeman, 2013).

\section{RESULTS AND DISCUSSION}

The parameters chosen to be analyzed and to fit correlations were: average flame height, average temperature profile adjacent to the tank and average radiative heat flux profile adjacent to the tank. Those important parameters were chosen since they are related to firefighting and to fire propagation to adjacent tanks.

The following empirical correlation can be employed to compute flame height ( $L_{f}$ - units $\left.\mathrm{m}\right)$ as a function of heat release rate ( $\dot{Q}$ - units $\mathrm{kW})$ and fire diameter ( $D$ - units m) (Quintiere, 2006):

$$
L_{f}=0.235 \dot{Q}^{\frac{2}{5}}-1.02 D
$$

Heat release rates $(\dot{Q})$ obtained in the present study were $18092.7 \mathrm{~kW}, 3200.3 \mathrm{~kW}, 656.7 \mathrm{~kW}$ and $106.9 \mathrm{~kW}$ for tanks of scales $1: 1,1: 2,1: 4$ and 1:8, respectively. Such values of $\dot{Q}$ were given as outputs from FDS, and they are function of burning rate (units $\mathrm{kg} /\left(\mathrm{m}^{2} . \mathrm{s}\right)$ ), combustion enthalpy (units $\mathrm{kJ} / \mathrm{kg}$ ) and surface area of fuel (units $\mathrm{m}^{2}$ ). Flame heights obtained from Equation (1) are presented in Table 2, whose agreement with FDS results (also presented in Table 2) is good. Instantaneous flame fields are shown in Fig. 2, where can be observed flame heights for each case simulated.

Table 2. Average flame height for real-scale and reduced-scales tanks.

\begin{tabular}{|c|c|c|}
\hline & \multicolumn{2}{|c|}{ Flame height [m] } \\
\hline Tank & FDS (Fig. 2) & $\begin{array}{c}\text { Eq. (1) } \\
\text { (Quintiere, 2006) }\end{array}$ \\
\hline$D=4.0 \mathrm{~m} \mathrm{(1:1)}$ & 8.0 & 7.8 \\
\hline$d=2.0 \mathrm{~m} \mathrm{(1:2)}$ & 3.8 & 3.9 \\
\hline$d=1.0 \mathrm{~m} \mathrm{(1:4)}$ & 2.1 & 2.2 \\
\hline$d=0.5 \mathrm{~m}(1: 8)$ & 1.1 & 1.0 \\
\hline
\end{tabular}

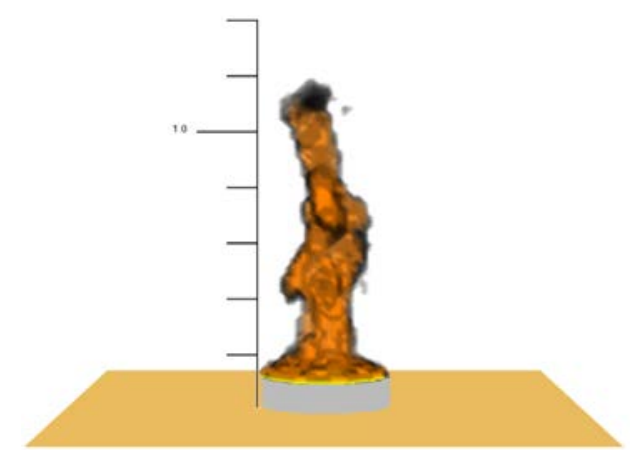

(a) $d=0.5 \mathrm{~m}(1: 8)$

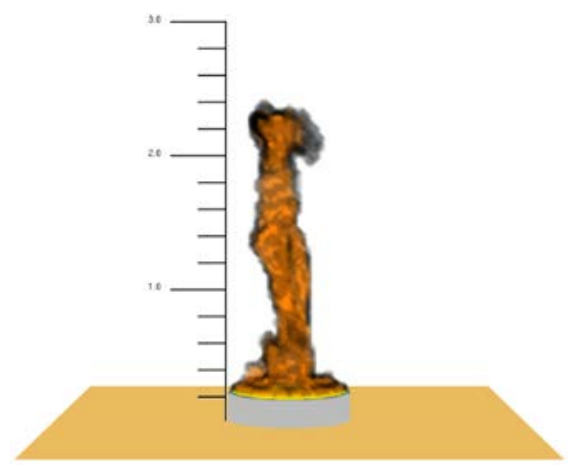

(b) $d=1.0 \mathrm{~m} \mathrm{(1:4)}$ 


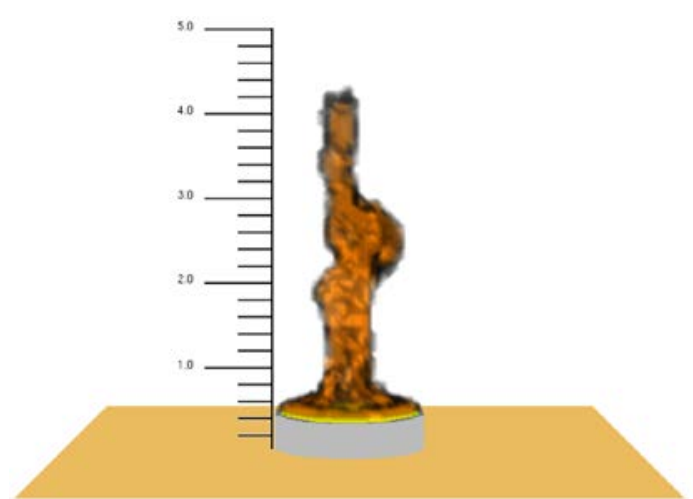

(c) $d=2.0 \mathrm{~m} \mathrm{(1:2)}$

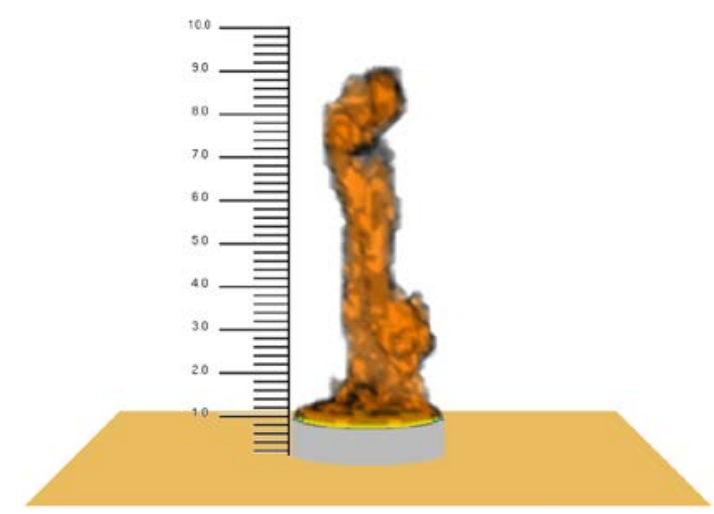

(d) $D=4.0 \mathrm{~m}(1: 1)$

Figure 2. Flame height for tanks of different scales: (a) $1: 8 d=0.5 \mathrm{~m}$, (b) $1: 4 d=1.0 \mathrm{~m}$,

(c) $1: 2 d=2.0 \mathrm{~m}$, (d) $1: 1 \mathrm{D}=4.0 \mathrm{~m}$.

The graph in Fig. 3 shows flame heights obtained for each simulation against tank diameter. It is observed a linear relationship between flame height and tank diameter. With those results, the following correlation can be fit:

$$
L_{f}=0.06522+1.96522 D
$$

where $L_{f}$ and $D$ are in meters. Equation (2) was specifically fit for ethanol storage tanks studied in the present work, and it serves as an estimative to easily obtain the flame height using as input the tank diameter only. Such equation is in contrast to Eq. (1) which has broader applicability but is function of heat release rate, a parameter that is not easily obtained.

Figure 4 presents average radiative heat flux profiles at ground level $(z=0 \mathrm{~m})$ for different $x$-positions from the tank wall (position $x=0 \mathrm{~m}$ corresponds to the position at the tank wall, while increasing $x$-positions correspond to distant position from the tank, as per Figure 1). Abscissa-axis of Fig. 4 was made dimensionless employing tank diameter (D) for each tank simulation. It is observed that radiative heat flux profile increases sharply from tank wall $(x=0 \mathrm{~m})$, reaching a maximum value at position $x / D \approx 0.3$, then decreasing smoothly as the distance from the tank increases. That behavior of the average radiative heat flux was the same for all tank sizes studied in the present work. It must also be noted that none of the tanks reached the human exposition limit of $5 \mathrm{~kW} / \mathrm{m}^{2}$, which could lead to serious burnings in case of exposition time higher than 60 seconds.

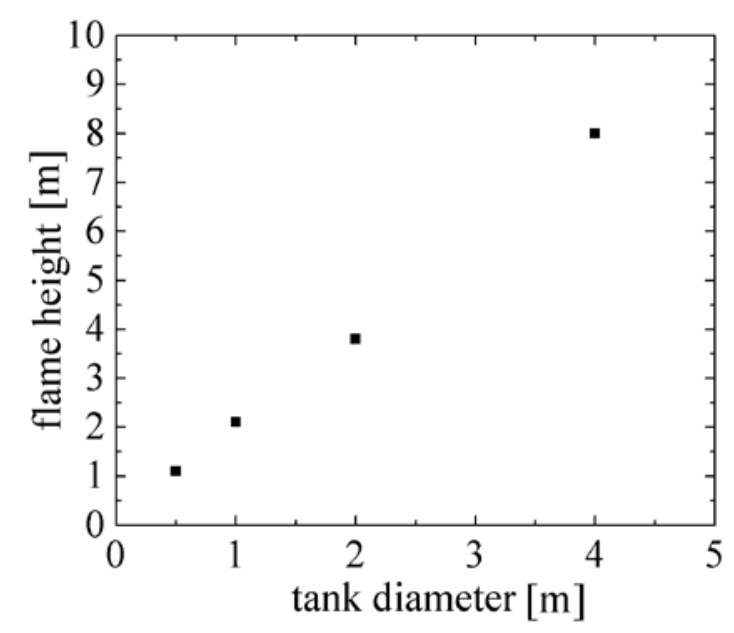

Figure 3. Flame heights $\times$ tank diameters: results for different scales.

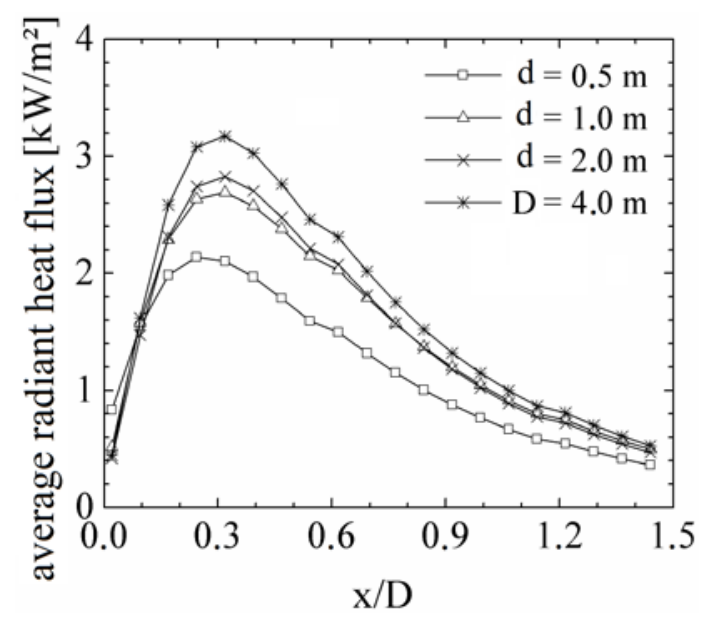

Figure 4. Average radiative heat flux profiles for different tank scales $(x / D=0$ corresponds to the position together with the tank wall).

$$
\begin{gathered}
\beta=1.113333-0.0175\left(\frac{D}{d}\right)+0.0079167\left(\frac{D}{d}\right)^{2} \\
q_{r a d, D}^{\prime \prime}=\beta \cdot q_{r a d, d}^{\prime \prime}
\end{gathered}
$$

Results obtained for the radiative heat flux profiles presented in Fig. 4 can be correlated in order to estimate the radiative heat flux profile for the realscale tank using as input a radiative heat flux profile for one of the reduced-scale tanks. Equation (3) was fit using data from Fig. 4. That equation provides parameter $\beta$, which is employed to obtain the radiative heat flux profile for the real-scale tank per 
Eq. (4). Where $D$ is the real-scale tank diameter (m), $d$ is the reduced-scale tank diameter $(\mathrm{m}), q_{\mathrm{rad}, D}^{\prime \prime}$ is the real-scale tank radiative heat flux profile $\left(\mathrm{kW} / \mathrm{m}^{2}\right)$, $q_{\text {rad,d }}^{\prime \prime}$ is the reduced-scale tank radiative heat flux profile $\left(\mathrm{kW} / \mathrm{m}^{2}\right)$. Equations (3) and (4) must be applied as follows: (i) compute the parameter $\beta$ using as inputs $D$ and $d$, (ii) compute the real-scale tank radiative heat flux profile ( $q_{\mathrm{rad}, \mathrm{D}}^{\prime \prime}$ ) using as input the reduced-scale tank radiative heat flux profile $\left(q_{\text {rad,d }}^{\prime \prime}\right)$.

Those correlations provide satisfactory percentage errors of $2.0 \%$ for the maximum radiative heat flux.

Figure 5 presents instantaneous temperature fields at physical time of 60 seconds. Despite the strong non-linear nature of the transport phenomena related to the process (turbulence, combustion, thermal radiation, etc.), Figure 5 shows that all instantaneous temperature fields have the same qualitative characteristics (approximately the same hot gas plume height and the same temperature distribution). It should be emphasized that hot gas plume heights shown in Fig. 5 are larger than flame heights shown in Fig. 2 since flame heights are related to the visible region of the flame while the upper portion of the hot gas plume is not visible (actually, it is at infrared region of radiation spectrum).
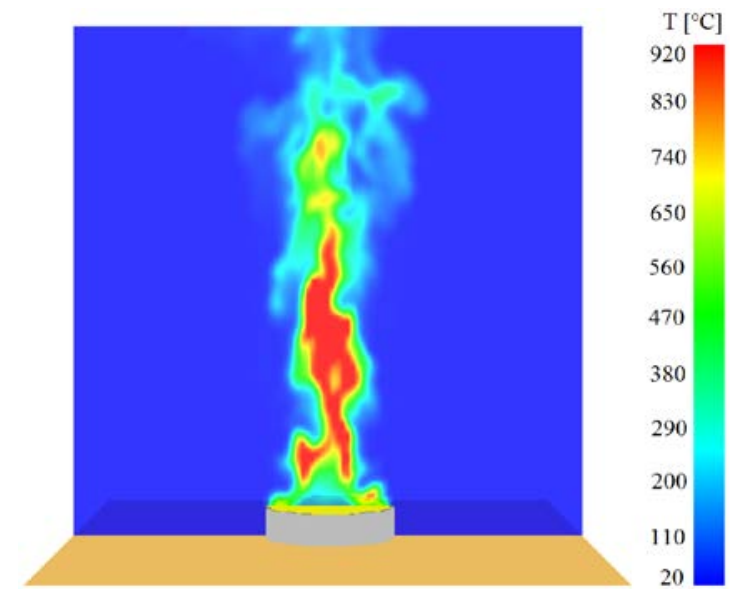

(a) $d=0.5 \mathrm{~m} \mathrm{(1:8)}$

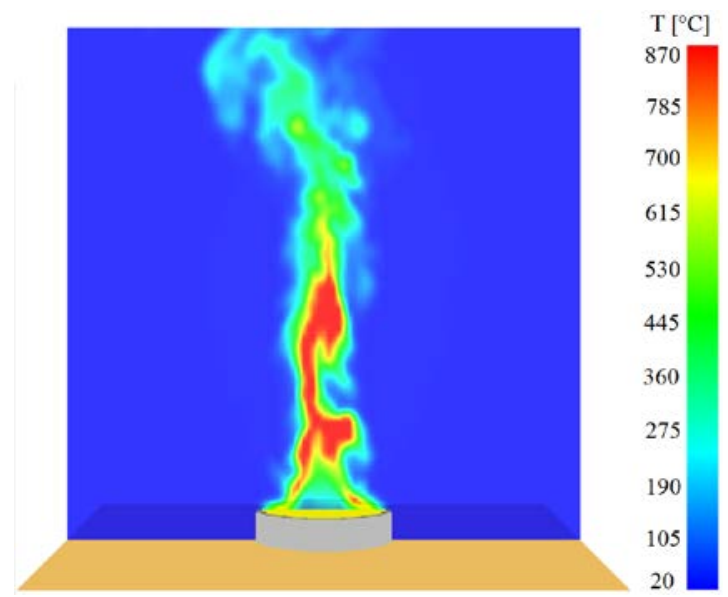

(b) $d=1.0 \mathrm{~m}(1: 4)$

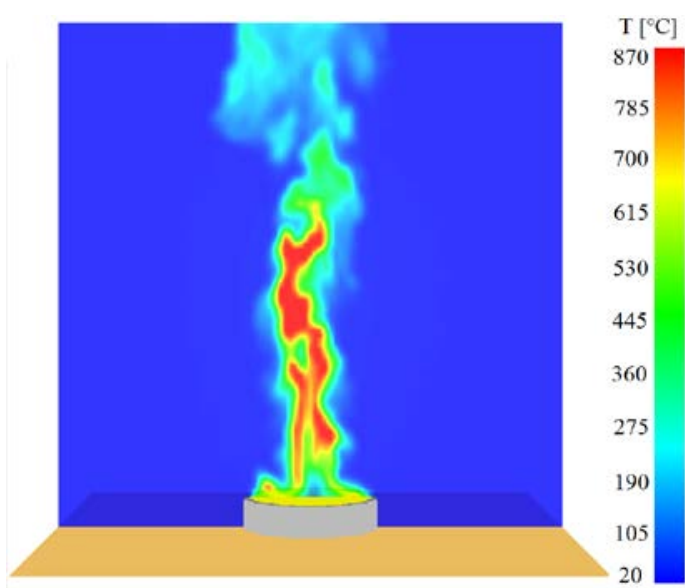

(c) $d=2.0 \mathrm{~m}(1: 2)$

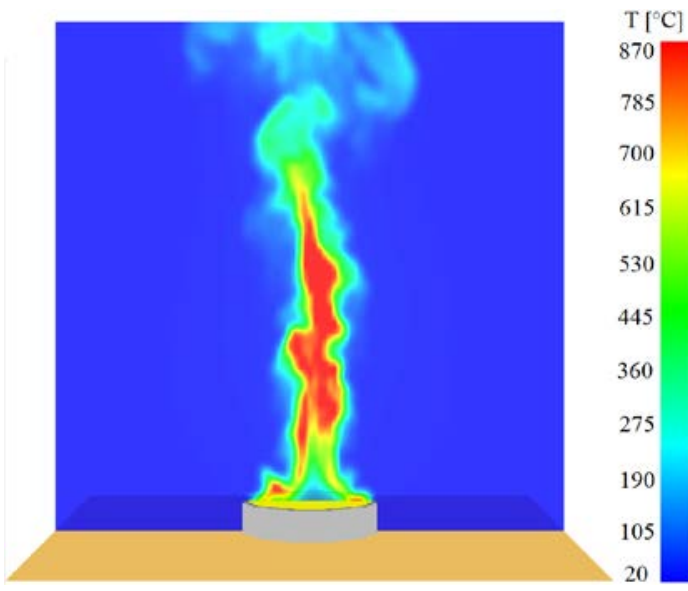

(d) $D=4.0 \mathrm{~m}(1: 1)$

Figure 5. Instantaneous temperature fields at physical time of 60 seconds.

Figure 6 shows average temperature profiles at different $x$-positions from the tank wall at $z=D / 4$ (coincident with tank top coordinate - see Figure 1). Abscissa-axis of Fig. 6 was made dimensionless employing tank diameter $(D)$ for each tank simulation. For every case under investigation average temperature profiles have peak temperatures close to the tank $(x / D \approx 0)$ and then those profiles smoothly decrease to ambient temperature $\left(20^{\circ} \mathrm{C}\right)$. Despite average temperature profiles have similar behavior for all tanks, it is observed at the region close do $x / D=0$ that such profiles present qualitative divergences, i.e., average temperature profile for tank of $4.0 \mathrm{~m}$ diameter has a positive slope close to $x / D=$ 0 , while such slope is negative for the other tanks. That qualitative divergence could be attributed to the energy release of each flame, so the larger flame has enough energy to warm ambient air further than the smaller flames, which have lower energy release. In this manner, the correlation fit to obtain average temperature profile for the real-scale tank from average temperature profile of a reduced-scale tank is function of both diameters ratio $(D / d$, where $D$ is real-scale tank diameter and $d$ is reduced-scale tank diameter) and position $x / D$. 


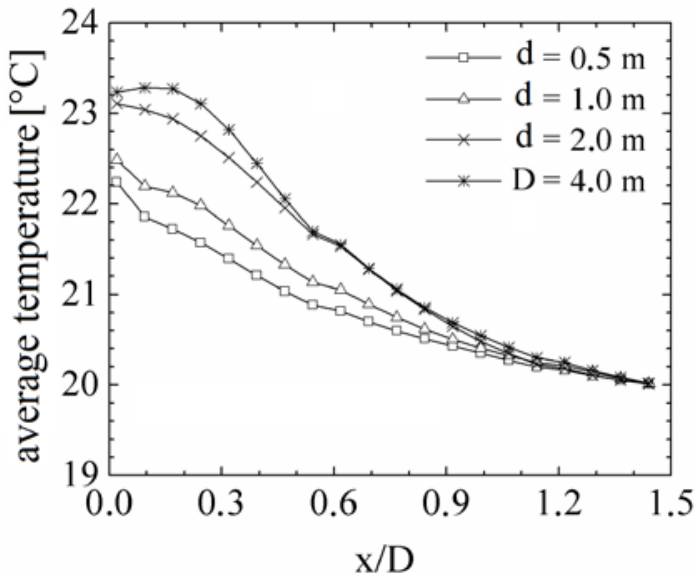

Figure 6. Average temperature profiles for different tank diameters $(x / D=0$ corresponds to positions together with tank wall).

$$
\begin{aligned}
T_{D}= & T_{d} \cdot\left(1.015-\frac{0.12}{D / d}\right) \cdot\left(1.04381+0.26535 \cdot\left(\frac{x}{D}\right)-. .\right. \\
& 0.83046 \cdot\left(\frac{x}{D}\right)^{2}+0.74717 \cdot\left(\frac{x}{D}\right)^{3}-\ldots \\
& \left.0.21788 \cdot\left(\frac{x}{D}\right)^{4}\right)
\end{aligned}
$$

where $T_{D}$ is the average temperature for real-scale tank $\left({ }^{\circ} \mathrm{C}\right)$ and $T_{d}$ is the average temperature for reduced-scale tank $\left({ }^{\circ} \mathrm{C}\right)$, both evaluated at the same position $x / D$. Employing Equation (5) to compute $T_{D}$, percentage errors are less than $4.5 \%$ and that error is even less than $0.6 \%$ at the highest temperature region $(0 \leq x / D \leq 0.5 \mathrm{~m})$.

\section{CONCLUSIONS}

This work presented a numerical study employing Large Eddy Simulation using the software FDS to predict flame heights, temperature profiles and radiative heat flux profiles adjacent to ethanol storage tanks under fire situation. Simulations considered different tank sizes: real-scale (1:1) and reduced-scales $(1: 2,1: 4,1: 8)$. The objective was correlating the results obtained from the different simulations for each tank size. Parameters chosen to be analyzed (flame height, temperature and radiative heat flux profiles) are important since they are related to firefighting and fire spread to adjacent tanks in a park of tanks.

Results shown that flame heights can be linearly correlated to the tank diameter. Other correlations available in literature to estimate flame height are functions of additional parameters, some of them difficult to obtain, demonstrating the importance of the present study. On the other hand, the simple linear correlation obtained in the present work was not validated to other fuels than ethanol, while correlations more complex are valid for a wide range of fuels through the heat release rate specification.

Correlations for average temperature profile and average radiative heat flux profile were also presented in this paper. Those profiles were considered at a region adjacent to each tank. Such correlations provide real-scale tank profiles of temperature and radiative heat flux using as inputs reduced-scale tank profiles of temperature and radiative heat flux. Once temperature profile or radiative heat flux profile at the region adjacent to a tank is available for a reduced-scale tank, computation of the correlations present in this work provides temperature profile and radiative heat flux profile for the real-scale tank. The correlation fit for the radiative heat flux profile is function of diameters ratio $(D / d)$ and it provided percentage error of less than $2.0 \%$ for the maximum radiative heat flux. The correlation fit for the temperature profile is function of both tank diameters $(D / d)$ and distance from the tank wall $(x / D)$. In that case, percentage errors were of $0.6 \%$ at the highest temperature region.

\section{ACKNOWLEDGEMENTS}

The authors acknowledge with gratitude the support of the Instituto Tecnológico em Desempenho e Construção Civil - itt Performance.

\section{REFERENCES}

Adam, B. A., Akafuah, N. K., Finney, M., Forthofer, J., and Saito, K., 2013, A Study of Flame Spread in Engineered Cardboard Fuelbeds - Part II: Scaling Law Approach, in: 7th International Symposium on Scale Modeling - ISSM-7, Hirosaki, Japan.

Bryner, N. P., Johnsson, E. L., and Pitts, W. M., 1995, Scaling Compartment Fires - Reduced and Full-Scale Enclosure Burns, in: International Conference on Fire Research and Engineering, Orlando, FL, USA.

Chang, J. I., and Lin, C., 2006, A Study of Storage Tank Accidents, Journal of Loss Prevention in the Process Industries, Vol. 19, pp. 51-59.

Deardorff, J. W., 1972, Numerical Investigation of Neutral and Unstable Planetary Boundary Layers, Journal of Atmospheric Sciences, Vol. 29, pp. 91115.

Godoy, L. A., and Batista-Abreu, J. C., 2012, Buckling of Fixed-roof Aboveground Oil Storage Tanks Under Heat Induced by an External Fire, ThinWalled Structures, Vol. 52, pp. 90-101.

Heymes, F., Aprin, L., Forestier, S., Slangen, P., Jarry, J. B., François, H., and Dusserre, G., 2013, Impact of a Distant Wildland Fire on an LPG Tank, Fire Safety Journal, Vol. 61, pp. 100-107.

Lin, C., and Wang, H., 2011, Research on Safety and Security Distance of Flammable Liquid Storage Tank, Engineering Procedia, Vol. 11, pp. 5160. 
McGrattan, K., Hostikka, S., Floyd, J., Baum, H., and Rehm, R., 2007, Fire Dynamics Simulator (Version 5): Technical Reference Guide, NIST Special Publication, NIST.

Overholt, K. J., Kurzawski, A. J., Cabrera, J., Koopersmith, M., and Ezekoye, O. A., 2014, Fire Behavior and Heat Fluxes for Lab-Scale Burning of Little Bluestem Grass, Fire Safety Journal, Vol. 67, pp. 70-81.

Qiang, S., Rongyi, M., Juan, L., Jiaxu, Z., Chunming, Z., and Jianshe, C., 2012, Numerical Simulation Study on Sprinkler Control Effect in UBS Fuel Tank Room of Nuclear Power Plants, Engineering Procedia, Vol. 43, pp. 276-281.

Quintiere, J. G., 1989, Scaling Applications in Fire Research, Fire Safety Journal, Vol. 15, pp. 3-29.

Quintiere, J. G., 2006, Fundamentals of Fire Phenomena, John Wiley \& Sons Ltd.

Ryder, N. L., Sutula, J. A., Schemel, C. F., Hamer, A. J., and Brunt, V. V., 2004, Consequence Modeling using the Fire Dynamics Simulator, Journal of Hazardous Materials, Vol. 115, pp. 149-154.

Silva, J. C., Antunes, F., Landesmann, A., and Ribeiro, F. L. B., 2013, Análise Numérica via Fluidodinâmica Computacional de Tanques de Armazenamento de Etanol sob Incêndio, in: $2^{\circ}$ Congresso Ibero-Latino-Americano sobre Segurança contra Incêndio - CILASCI, Coimbra, Portugal. (in Portuguese)

Stroup, D., and Lindeman, A., 2013, Verification and Validation of Selected Fire Models for Nuclear Power Plant Applications, NUREG-1824, Supplement 1, United States Nuclear Regulatory Commission, Washington, DC.

Wen-he, W., Zhi-sheng, X., and Bao-jiang, S., 2013, Numerical Simulation off Ire Termal Radiation Field for Large Crude Oil Tank Exposed to Pool Fire, Engineering Procedia, Vol. 52, pp. 395-400.

Zhang, P., Zhang, Y., Tian, X., and Ji, T., 2014, Small Scale Experiment Study on the Fireproof Distance of Oil Tank Fires, Procedia Engineering, Vol. 71, pp. 486-491.

Zheng, J., Ou, K., Hua, Z., Zhao, Y., Xu, P., Hu, J., and Han, B., 2013, Experimental and Numerical Investigation of Localized Fire Test for HighPressure Hydrogen Storage Tanks, International Journal of Hydrogen Energy, Vol. 38, pp. 1096310970. 